\title{
Design Strategies to Reduce the Impact of Visual and Noise Pollution in Urban Areas
}

\section{Sritharan Sahana ${ }^{\circledR}$ (D) Sacthivel Karthigayini ${ }^{2}$}

Postgraduate Institute of Agriculture, University of Peradeniya, Peradeniya, Sri Lanka. Email:srisahana1992@gmail.com Tel:0094772934475

Email: ammusacthivel@gmail.com Tel:0094776119687

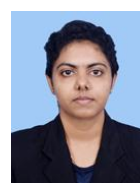

( Corresponding Author)

\section{Abstract}

Noise and visual pollution are major arising pollution in the world. These types of pollution cause negative impacts on the inhabitants of the inbuilt environment or on the outside communities. Visual pollution affects the overall wellbeing of the community and retards quality of life. Moreover, noise pollution arises mainly from transportation, construction, industrialization and electronic equipment or tools. This study was carried out to mitigate the noise and visual pollution by proposing basic design strategies that can be applicable anywhere. Proper town and building planning could be a better option with noise tolerant buildings and noise barriers. In addition, building designs and selection of suitable construction materials also have to be considered in mitigating noise and visual pollution. However, it is mainly the responsibility of the decision makers of the society to make the development look and feel better as well as of the designers and planners to implement proper methods to ensure that the community fits the regulations.

Keywords: Noise pollution, Visual pollution, Design strategies, Town planning, Noise barriers, Green ways.

Citation | Sritharan Sahana; Sacthivel Karthigayini (2020). Design Strategies to Reduce the Impact of Visual and Noise Pollution in Urban Areas. Asian Review of Environmental and Earth Sciences, $7(1): 67-71$.

History:

Received: 24 April 2020

Revised: 26 May 2020

Accepted: 30 June 2020

Published: 28 July 9090

Licensed: This work is licensed under a Creative Commons

Attribution 3.0 License (c) $)$ E

Publisher: Asian Online Journal Publishing Group
Acknowledgement: Both authors contributed to the conception and design of the study.

Funding: This study received no specific financial support.

Competing Interests: The authors declare that they have no conflict of interests.

Transparency: The authors confirm that the manuscript is an honest, accurate, and transparent account of the study was reported; that no vital features of the study have been omitted; and that any discrepancies from the study as planned have been explained.

Ethical: This study follows all ethical practices during writing.

\section{Contents}

1. Introduction

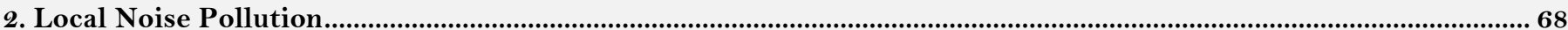

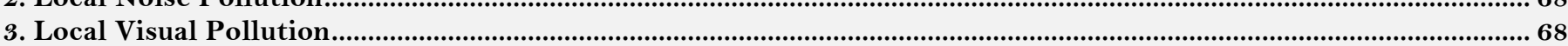

4. Conclusion .1.2.

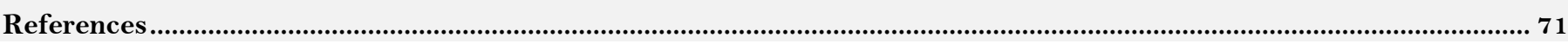




\section{Contribution of this paper to the literature}

This study was carried out to mitigate the noise and visual pollution by proposing basic design strategies that can be applicable anywhere.

\section{Introduction}

In the recent years of economic and infrastructure development, communities and designers have shown a great interest at moving towards a more environmentally friendly development. This is done in order to minimize the pollution caused due to human needs and to improve the quality of life.

Although any type of pollution is alarming as highlighted [1]. Light, visual and noise pollution are the least discussed and least concerned of. These ignored types of pollution should also be looked into more often as these are the first factors any one could easily detect about a community and causes negative impacts on the inhabitants of the inbuilt environment or on the outside communities.

Visual pollution is an aesthetic issue and refers to the impacts of pollution that impairs one's ability to enjoy a view. Visual pollution is a compounded effect of clutter, disorder, and excess of various objects and graphics in the landscape, such as outdoor advertisements, street furniture, lighting features [2] vegetation characteristics [3] and other objects. Visual pollution ranges from overcrowding a built environment with visually unappealing items to non-aesthetical irregular formations found in built environments. This causes little more than annoyance in certain cases. Visibility is a measure of how well one can see. Due to obscuring visions such as haze because of vehicle emissions, industries and unidentifiable road signs it puts road users in immediate danger. Moreover, as shown in a study conducted in parts of India the effects of visual pollution proves that it affects the overall wellbeing of the community, hinders quality of life, psychological effects, eye fatigue, distraction, feeling of disorganization, irritability and loss of community identity [4].

Noise pollution arises from unnecessary or prolonging unnatural sound. In a built environment any sound that disrupts the natural rhythm of life such as sleeping, relaxing, and studying and degrading the standard of life is considered as noise pollution. The main reason for noise pollution is the lack of urban planning [5]. In built environments sound from transportation (land and sky), construction, industrialization and electronic equipment or tools contributes to noise pollution. Although noise pollution is not considered adverse compared to water or air pollution, it has pronounced and immediate detectable effects such as, heart problems, hearing problems, communication issues, sleeplessness, adverse mental health issues, decreased concentration and increase of stress [6].

In the local towns visual and noise pollution can be seen and heard in abundance. Especially during voting season social visual and noise balance is regarded very poorly. This even led to several Government Environmental Authorities to appeal to the Court of Law to implement a regulation on banners during election periods.

Noise and Visual pollution are unfortunately not a seasonal issue in towns of Sri Lanka. Communities are subjected to it daily due to poor standards of the local public transportation, little or no town planning and less than effective regulatory bodies to safeguard the general wellbeing of the people.

In this study the local sources of pollution are to be explained and applicable design strategies to mitigate and control pollution will be discussed.

\section{Local Noise Pollution}

Most of the time there is a lack of separation between Residential, Commercial and Social areas.

Almost all the vehicle running on the local streets causes cause a massive amount of noise throughout the day regardless of whether they are diesel or petrol engines or private or public vehicles. Therefore, it is obvious that these residents living along the roads suffer due to extreme noise especially during traffic hours.

Residential areas and schools neighboring large-scale industries and construction sites are always subjected to noise pollution due to heavy machinery and power tools.

\section{Local Visual Pollution}

Any type of local ad campaign as common practice habitually soils local walls, road signs even gates. The sign boards are usually flooded with posters and are visually messy and unappealing.

Visual graphics (Billboards) are the prominent features in wrong places of the urban cities completely blocking the roads, thereby obstructing the traffic as well as pedestrians view [7].

Messy, low hanging and unattractive power cables and telephone lines can frequently be seen around local towns. In addition, it blocks beautiful scenery which has a negative impact on the tourism industry and the cultural values.

The buildings usually found outside the city limits are not the most architecturally well thought out buildings. Even though an effort on this area is being made the towns are filled with poorly designed buildings.

This is not a day to day major issue in Sri Lanka but as observed during election season becomes a severe nuisance to the public as the streets are flooded with campaign cut outs.

In the name of development many lands are being cleared and trees are being cut creating an unnatural unhealthy environment. This is especially true when it comes to real estate lands. Hence the towns are slowly losing their green and natural features.

After having studied the local causes of noise and visual pollution the following design strategies are proposed in hope of mitigating or controlling the problem. The strategies given are through literature review are the most basic solutions applicable anywhere.

\subsection{Town and Building Planning}

A number of town planning strategies as well as building planning designs are described specially to mitigate the impacts of noise pollution in urban development. Some strategies can be used to reduce the visual pollution impacts as well. 
Land use planning is often seen with less priority in mitigating noise pollution. However, it has a greater role in reducing noise. Outlining zoning plans can be drawn to govern land uses for different purposes. This is to say that the area of land can be separated into different zones such as for the residential purposes, commercial purposes and industrialized purposes to avoid compatibility in land use.

And also, a buffer zone can be suggested between the zones to further reduce any noise impact from the industrialized zones to other zones.

By land zoning, proper town planning can be put into practice and areas with different levels of noise sensitivity can be maintained within the zones. Also, all traffic will also be diverted away from the residential areas improving the quality of the general public.

In addition to that, within communities it is important to provide space for the public to express themselves. A centralized place for all billboards to hang, enough notification boards for all posters and municipal maintenance of these services. By zoning out special such areas the spread visual pollution could be limited to only certain locations. It is also possible to make these places more aesthetically appealing and to get the communities together. For example, graffiti walls at public parks to express creativity and opinions. Hence building a more visually pleasant environment.

Another major factor to take into consideration when town planning is where the municipal landfills and dumping yards would be placed. Landfills and dump yards should be located away from the residential and commercial areas in order to create a more visually appealing surrounding.

\subsection{Screening by Noise Tolerant Buildings}

For commercial or residential buildings located along the side of busy roads this is great measure to reduce the impact of noise. A noise tolerant structure can be placed between the busy road and the building thus creating a shadow zone on the building. Due to the noise tolerant structure the noise in the shadow zone is reduced. The noise tolerant structure could be a multi-story car park.

\subsection{Decking}

Decks or tunnels can be built on roads near noise sensitive buildings. The noise impact on the building can be greatly reduced due to that structure.

The above-mentioned features can also be used as architecturally eye-catching elements in built environments. Attractive development provides pleasing aesthetical surroundings reducing the impacts of visual pollution.

\subsection{Noise Barriers}

Noise barriers of different kinds can be installed around noise sensitive buildings to interrupt the propagation of the sound waves.

\subsubsection{Oriented Noise Barrier}

An acoustical shadow zone can be created behind the barrier designed with proper selection of material reducing the noise impact on the building. Noise levels are reduced primarily through diffraction over the top of the barrier and around its ends. The barriers can either be vertical or cantilevered.

\subsubsection{Green Barrier}

This type of barrier has been in trend for some time now. A green barrier can be grown around the building in order to reduce the noise at least by $15 \mathrm{~dB}$ [8] where geotextile based green walls (Figure 1) supports the plant without a substrate. This can be in the form of a green wall, green fin or a planted space. Green barriers or trees have the ability to absorb the sound waves which can be a passive acoustic insulation system for buildings.

Green and planted areas are pleasant to look at. If there is an unpleasant neighborhood or a view the best solution is to also plant a green barrier of maybe bamboo along the perimeter of the building which would block the ugly view. Incorporating living green elements in built environments can drastically improve the appearance hence reducing visual pollution. Also, rather than completely clearing off lands if any trees are in the way of possible it is better to try and build around it or incorporate the tree into the design as much as possible.

In addition to including green elements outside the buildings green features can also be used inside the buildings. Especially in office spaces instead of in-built block or wood partition walls, mobile green walls or planted walls can be placed inside the building to separate the office space.

\subsection{Construction Material}

Impacts of noise can also be reduced by variating the materials used in constructing structures.

\subsubsection{Road Paving}

To reduce the heavy noise created due to road tyre interaction during high speed traffic, a different material can be used to pave the roads instead of concrete or standard bitumen paving. The normal paving materials with microscopic grooves cause the noise to resonate hence increasing the noise created due to tyre road interaction.

An open textured bituminous highway surfacing can be used to pave surfaces near noise sensitive buildings. This surface contains tiny holes making $20 \%$ of the volume which absorbs the noise from road tyre interaction reducing the noise by up to $5 \mathrm{db}$.

\subsubsection{Building Material}

When developing buildings around heavy noise areas such as around airports sound insulation material can be used to layer the roof or walls in order to reduce the external noise absorbed in the building. 


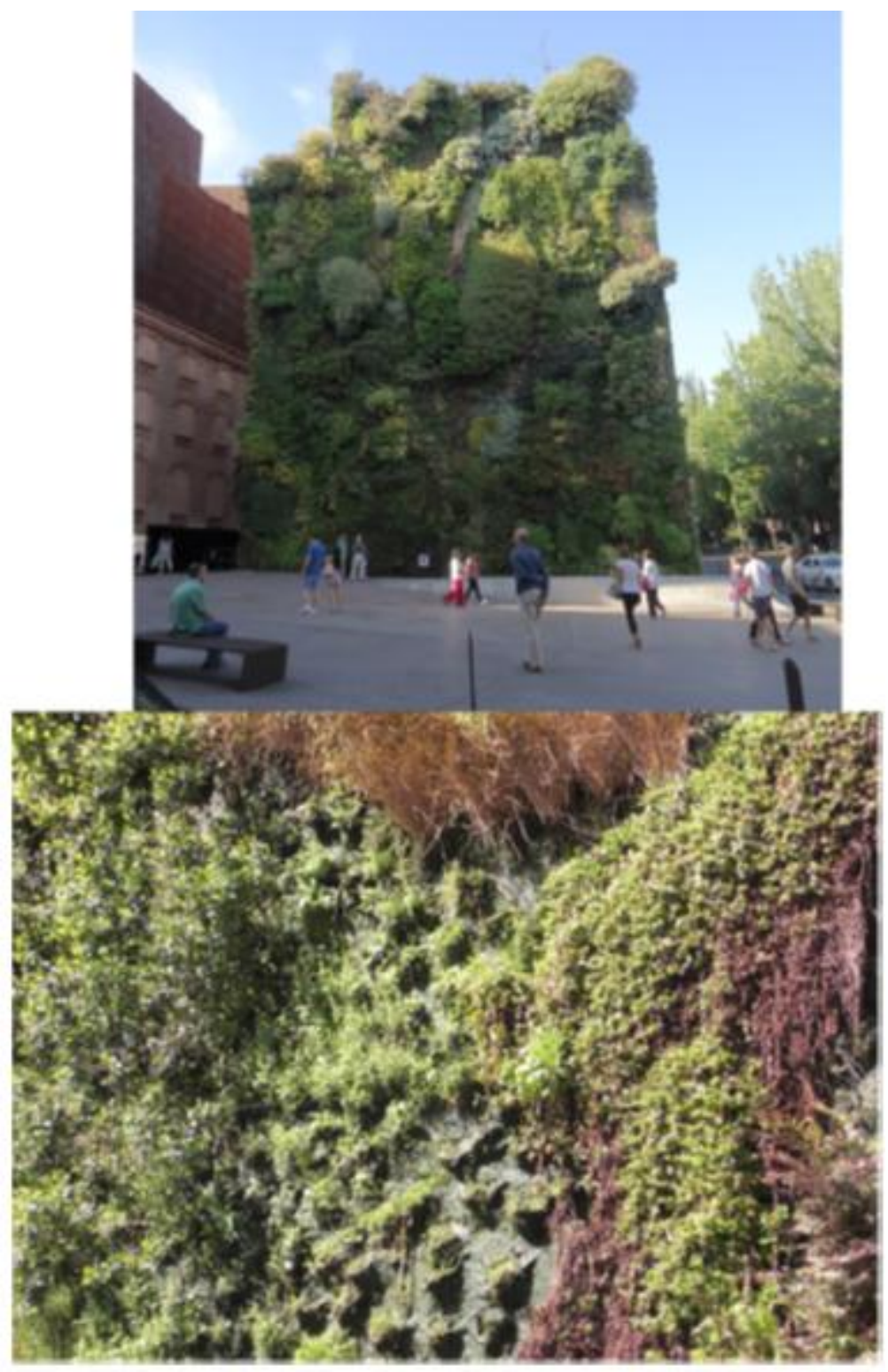

Source: Azkorra, et al. [8].

\subsection{Traffic and Noise Control}

In addition to the designs that can be incorporated in to build environments to reduce sound pollution it can be further mitigated by the technology used at the sources of the problem. Electric motors produce less sound than internal combustion engines. Therefore, the mitigation of noise pollution can be promoted by promoting the use of electronic vehicles.

Traffic is also a source of visual pollution therefore organized motorways and high way designs would be more visually appealing compared to messy and disorganized motorways. Also, in a built environment the traffic carrying structures could be built either surrounding the communities to avoid the view of the built environment seem less messy.

\subsection{Organized Utility Provisions}

Wires and cables pulled around development for the provision of services should be stretched to avoid it being hung over, drooping and disarranging the space. Also, when these cables are pulled across areas with valuable scenery the service provisions could be given via underground cables therefore not disrupting the vista.

\subsection{Building Openings}

In a built structure the window and door openings should be oriented such that they do face an unpleasant view. Instead they should be oriented as much as possible towards the pleasant most possible view.

Also, the openings of a building surrounded with unattractive buildings, the window openings could be placed at a higher position on the walls so that only the space above these buildings such as the skies and surrounding trees are visible. This could also be dealt with using height adjustable window shades.

\section{Conclusion}

Noise and Visual pollution are constantly around and any built environment could be easily subjected to it. Even though no immediate serious health or environment hazards are roused due to these types of pollution it brings about immense irritation and disorganization to the image of the community. This hence will have long term effects to the human and environmental wellbeing of the said community.

By studying the before mentioned noise and visual impact mitigation strategies it does not seem impossible to avoid pollution of this kind. Most of the causes for noise and visual pollution could be mitigated through better town planning, traffic laws, environmental regulations and innovative nondestructive building designs. Therefore, it is mainly the responsibility of the decision makers of the society to make the development look and feel better as 
well as of the designers and planners to implement proper methods to ensure that the community fits the regulations.

By providing a more visually attractive and audible tranquil developed environment a community would be viewed as a more organized and healthier.

The authorities would also have a better chance at functioning a more visually and audibly appealing development if the users or the communities are better educated on visual and noise pollution through awareness programs. This would ensure sustainability of noise and visual pollution mitigation strategies.

\section{References}

[1] A. Klazema, "Types of environmental pollution: Understanding their causes, Udemy blog, web log post, 6 April. Retrieved from: https://blog.udemy.com/types-of-environmental-pollution/. [Accessed 17 October 2016]," 2014.

[2] F. Falchi, P. Cinzano, C. D. Elvidge, D. M. Keith, and A. Haim, "Limiting the impact of light pollution on human health, environment and stellar visibilit," Journal of Environmental Management, vol. 92, pp. 2714-2722, 2011. Available at: 10.1016/j. jenvman.201 1.06.029.
L Ribeiro and T. Barao, "Greenways for recreation and maintenance of landscape quality: Five case studies in Portugal," Landscape

[3] L. Ribeiro and T. Barao, "Greenways for recreation and maintenance of landscape quality: Five case studies in Portugal," Landscape
and Urban Planning;, vol. 76, pp. 79-97, 2004. Available at: 10.1016/j. landurbplan.2004.09.042.
M. K. Jana and T. De, "Visual pollution can have a deep degrading effect on urban and suburban community: A study in few places of Bengal, India, with special reference to unorganized billboards," European Scientific Journal, vol. 11, pp. 11-14, 2015.

[5] Rinkesh, "Understanding noise pollution, conserve energy future blog, web log post. Retrieved from: http://www.conserveenergy-future.com/causes-and-effects-of-noise-pollution.php. [Accessed 17 October 2016]," 2009.

[6] R. Agrawal, "Noise pollution: Causes, effects \& solutions for control. b4tea blog, web log post. Retrieved from: R. Agrawal, "Noise pollution: Causes, effects \& solutions for control. b4tea blog, web $\log$ post. Retrieved from:
http://b4tea.com/information/noise-pollution-causes-effects-solutions-for-control/. [Accessed 18 October 2016]," 2012. O. E. Bankole, "Urban environmental graphics: Impact, problems and visual pollution of signs and billboards in Nigerian cities," International Journal of Education and Research, vol. 1, pp. 1-12, 2013.

[8] Z. Azkorra, G. Pérez, J. Coma, L. F. Cabeza, S. Burés, J. E. Álvaro, and M. Urrestarazu, "Evaluation of green walls as a passive acoustic insulation system for buildings," Applied Acoustics, vol. 89, pp. 46-56, 2015. Available at: https://doi.org/10.1016/j.apacoust.2014.09.010. 